\section{Deprotonative Coupling of Pyridines with Aldehydes Catalyzed by an HMDS-Amide Base Generated in Situ}

\author{
Masanori Shigeno,* Kunihito Nakaji, Akihisa Kajima, \\ Kanako Nozawa-Kumada, and Yoshinori Kondo*
}

Department of Biophysical Chemistry, Graduate School of Pharmaceutical Sciences, Tohoku University; Aoba, Sendai 980-8578, Japan.

Received July 17, 2019; accepted August 6, 2019

Herein, the deprotonative functionalization of pyridine derivatives with aldehydes under ambient conditions has been demonstrated using an amide base generated in situ from a catalytic amount of $\mathrm{CsF}$ and a stoichiometric amount of tris(trimethylsilyl)amine (N(TMS) $)_{3}$ ). Pyridine substrates bearing two electron-withdrawing substituents (i.e., fluoro, chloro, bromo, and trifluoromethyl moieties) at the 3 - and 5 -positions efficiently react at the 4-position with various aldehydes including arylaldehydes, pivalaldehyde, and cyclohexanecarboxaldehyde.

Key words pyridine; deprotonative functionalization; amide base generated in situ

\section{Introduction}

Pyridine is a key structural motif in pharmaceutical, agrochemical, and materials science. The deprotonative functionalization of pyridines with electrophiles has been widely used to synthesize a variety of pyridine derivatives. ${ }^{1-10)}$ Strong Brønsted bases such as $n$-BuLi, sec-BuLi, lithium diisopropylamide (LDA), and lithium tetramethylpiperidide (LiTMP) are employed in the deprotonation step to prepare the requisite pyridyl lithium species (Fig. 1a, upper scheme). ${ }^{1-6)}$ The reactions are usually performed under cryogenic conditions, which

(a) Conventional protocols

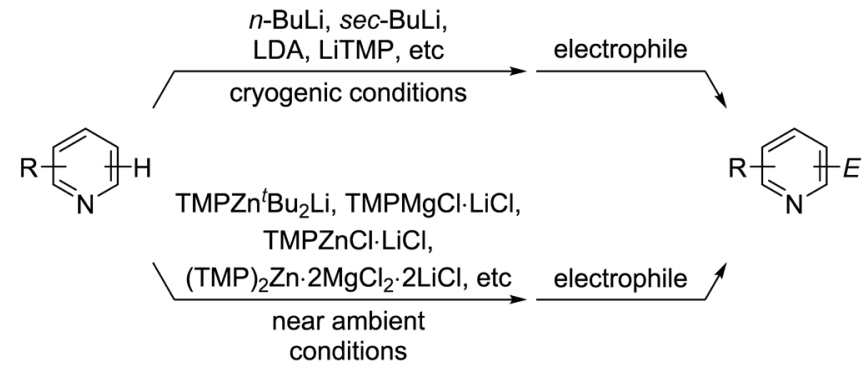

(b) This work: In situ generated amide base catalysis

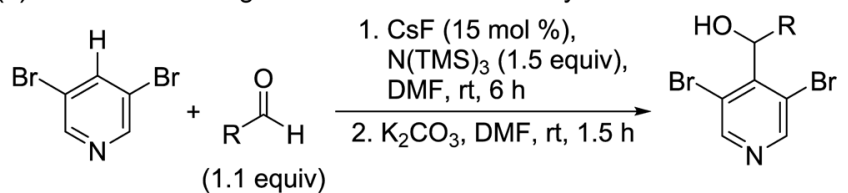

- Ambient conditions

- Good functional group tolerance

Fig. 1. Deprotonative Functionalization of Pyridine Derivatives with Electrophiles aim at inhibiting the temperature increase observed during this exothermic process and to restrain any side-reactions involving the lithiated species, such as nucleophilic addition onto an electrophilic substituent as well as the halogen dance reaction and aryne formation in the case of halogenated substrates. Protocols using milder bases, such as magnesium- and zinc-derived reagents, have also been developed, which can be conducted at near ambient conditions with high functional group tolerance (Fig. 1a, lower scheme). ${ }^{6,711-23)}$ However, the preparation of these reagents requires the use of stoichiometric amounts of several chemical reagents. Hence, further development of an efficient protocol to perform this transformation is still imperative in organic chemistry.

Our group has previously reported the deprotonative functionalization of $\mathrm{C}-\mathrm{H}$ bonds in pronucleophiles using a hexamethyldisilazide (HMDS)-amide base generated in situ using a catalytic amount of a fluoride or alkoxide salt and a stoichiometric amount of tris(trimethylsilyl)amine $\left(\mathrm{N}(\mathrm{TMS})_{3}\right){ }^{24-34)}$ The system efficiently catalyzes the reaction of heteroarenes, methyl(hetero)arenes, acetate, and terminal alkynes with electrophiles such as carbonyl and polyfluoroarene compounds. The heteroarenes employed in the reaction include fivemembered heterocyclic compounds such as (benzo)thiophene, benzofuran, benzothiazole, and indole derivatives. Herein, we report that this reaction system is applicable toward the transformation of pyridine derivatives; for example, 3,5-dihalopyridines react with a variety of aldehydes (1.1 equiv) under

Table 1. Optimization of the Coupling Reaction between $\mathbf{1 a}$ and $\mathbf{2} \mathbf{a}^{a}$

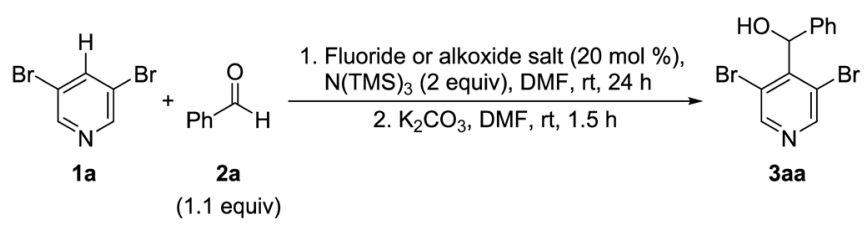

\begin{tabular}{|c|c|c|c|}
\hline Entry & Fluoride or alkoxide salt & Solvent & Yield $(\%)^{b)}$ \\
\hline 1 & $\mathrm{KF}$ & DMF & 0 \\
\hline 2 & $\mathrm{RbF}$ & DMF & 32 \\
\hline 3 & $\mathrm{CsF}$ & DMF & quant. \\
\hline 4 & TMAF $^{c)}$ & DMF & 38 \\
\hline 5 & $\mathrm{TBAT}^{d)}$ & DMF & 93 \\
\hline 6 & $\mathrm{NaOEt}$ & DMF & 69 \\
\hline 7 & $\mathrm{NaO}-t-\mathrm{Bu}$ & DMF & 85 \\
\hline 8 & $\mathrm{KO}-t-\mathrm{Bu}$ & DMF & 81 \\
\hline 9 & $\mathrm{CsCl}$ & DMF & 0 \\
\hline 10 & CsI & DMF & 0 \\
\hline 11 & $\mathrm{CsF}$ & DMA & 76 \\
\hline 12 & $\mathrm{CsF}$ & DMSO & 95 \\
\hline 13 & $\mathrm{CsF}$ & NMP & 77 \\
\hline 14 & $\mathrm{CsF}$ & DMI & 87 \\
\hline 15 & $\mathrm{CsF}$ & $\mathrm{THF}$ & trace \\
\hline 16 & $\mathrm{CsF}$ & $\mathrm{Et}_{2} \mathrm{O}$ & 0 \\
\hline 17 & $\mathrm{CsF}$ & Toluene & 0 \\
\hline 18 & $\mathrm{CsF}$ & DMF & quant. $(97)^{e, f)}$ \\
\hline
\end{tabular}

a) Reactions were conducted on a $0.2 \mathrm{mmol}$ scale. $b$ ) Yields were determined by ${ }^{1}$ H-NMR analysis. $c$ ) Tetramethylammonium fluoride. $d$ ) Tetrabutylammonium difluorotriphenylsilicate. $e$ ) The yield reported in the parenthesis denotes the isolated yield. f) Reaction was conducted using $\mathrm{CsF}(15 \mathrm{~mol} \%)$ and $\mathrm{N}(\mathrm{TMS})_{3}$ (1.5 equiv) for $6 \mathrm{~h}$. 
ambient conditions (Fig. 1b).

\section{Results and Discussion}

At the beginning of this research project, the reaction conditions were investigated using 3,5-dibromopyridine (1a) and benzaldehyde (2a) as model substrates ${ }^{35)}$ (Table 1). Among the fluoride salts examined, $\mathrm{CsF}$ was the most effective and formed the desired coupling product (3aa) in quantitative yield (entries 1-5). Alkoxide salts including $\mathrm{NaOEt}, \mathrm{NaO}-t$-Bu, and $\mathrm{KO}-t-\mathrm{Bu}$ can also be used in the reaction, however, they were inferior to $\mathrm{CsF}$ (entries 6-8). $\mathrm{CsCl}$ and $\mathrm{CsI}$ did not give 3aa (entries 9 and 10). Subsequently, the solvent effect on the reaction was examined (entries 11-17). Using aprotic polar solvents such as $N, N$-dimethylacetamide (DMA), dimethyl sulfoxide (DMSO), 1-methyl-2-pyrrolidone (NMP), and 1,3-dimethyl-2-imidazolidinone (DMI) afforded the target product in good yields, while the reaction did not proceed in tetrahydrofuran (THF), $\mathrm{Et}_{2} \mathrm{O}$, and toluene. Finally, when the reaction was conducted using decreased amounts of CsF (15 mol\%) and $\mathrm{N}(\mathrm{TMS})_{3}$ (1.5 equiv) for a shorter reaction time $(6 \mathrm{~h}), \mathbf{3 a a}$ was still isolated in a high yield (97\%) (entry 18).
With the optimal conditions in hand, the substrate scope of the reaction was investigated using a range of pyridine (1) and carbonyl (2) compounds (Fig. 2). 3,5-Dichloropyridine (1b) and 3,5-difluoropyridine (1c) coupled with $\mathbf{2 a}$ to provide the target products in 94 and 74\% yields, respectively. 3-Chloro-5(trifluoromethyl)pyridine (1d) also reacted with 2a to form the desired product in $42 \%$ yield. The reactions of $\mathbf{1 a}$ and $\mathbf{1 b}$ with pivalaldehyde (2b) furnished $\mathbf{3} \mathbf{a b}$ and $\mathbf{3 b b}$ in $98 \%$ and $94 \%$ yields, respectively. Mono-halogenated pyridines $\mathbf{1 e}$ and $\mathbf{1 f}$ were also employed in the reaction, however, the target products were produced in low yields (12\% and 14\%, respectively). Arylaldehydes other than $\mathbf{2 a}$ were also applied in the reaction. Ortho- and para-methyl-substituted $\mathbf{2 c}$ and $\mathbf{2 d}$ reacted with 1a to form 3ac and 3ad in 98 and $82 \%$ yields, respectively. Compounds $\mathbf{2 e}$ and $\mathbf{2 f}$ bearing electron-donating methoxy and dimethylamino groups also underwent the reaction to give their corresponding products in $91 \%$ and $80 \%$ yields, respectively. Chloro- and bromo-substituents were tolerated in the reaction and gave alcohols $\mathbf{3 a g}$ and $\mathbf{3 a h}$ in $92 \%$ and $80 \%$ yields, respectively. When employing substrate $\mathbf{2 i}$ bearing an ester moiety in the reaction, product 3ai was isolated in $45 \%$

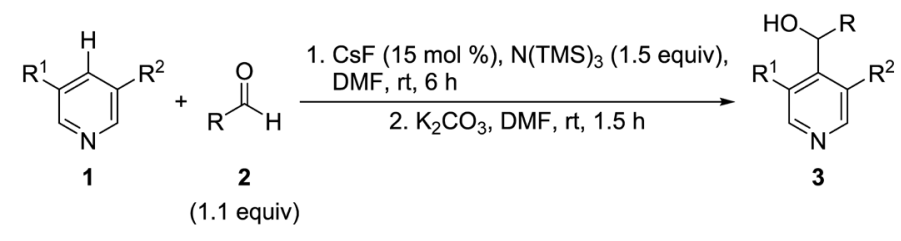<smiles>OC(c1ccccc1)c1c(Cl)cncc1Cl</smiles>

3ba, $94 \%$<smiles>CC(C)(C)C(O)c1c(Cl)cncc1Cl</smiles>

3bb, $94 \%$<smiles>Cc1ccc(C(O)c2c(Br)cncc2Br)cc1</smiles>

3ad, $82 \%$<smiles>OC(c1ccc(Br)cc1)c1c(Br)cncc1Br</smiles>
3ah, $80 \%$<smiles>OC(c1cc2ccccc2s1)c1c(Br)cncc1Br</smiles>

3al, $47 \%^{c}$<smiles>OC(c1ccccc1)c1c(F)cncc1F</smiles>

3ca, $74 \%$<smiles>CC(C)(C)C(O)c1ccncc1Br</smiles>

3eb, $12 \%$<smiles>COc1ccc(C(O)c2c(Br)cncc2Br)cc1</smiles>

3ae, $91 \%$<smiles>CC(=O)c1ccc(C(O)c2c(Br)cncc2Br)cc1</smiles>
3ai, $45 \%^{\mathrm{c}}$<smiles>OC(c1cccnc1)c1c(Br)cncc1Br</smiles>

3am, $69 \%^{\mathrm{C}}$<smiles>OC(c1ccccc1)C(Cl)c1cncc(Cl)c1C(F)(F)F</smiles>

3da, $42 \%$<smiles>CC(C)(C)C(O)c1cncc(Cl)c1</smiles>

3fb, $14 \%$<smiles>CN(C)c1ccc(C(O)c2c(Br)cncc2Br)cc1</smiles>

3af, $80 \%$<smiles>OC(c1ccc2ccccc2c1)c1c(Br)cncc1Br</smiles>

3aj, $92 \%$<smiles>CC(C)(C)C(O)c1c(Br)cncc1Br</smiles>

3ab, $98 \%$<smiles>O=[N+]([O-])c1ccccc1C(O)c1c(Br)cncc1Br</smiles>

3ac, $98 \%$<smiles>OC(c1ccc(Cl)cc1)c1c(Br)cncc1Br</smiles>

3ag, $92 \%$

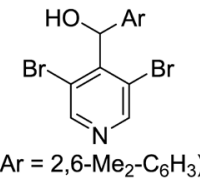

3ak, $78 \%$

Fig. 2. Substrate Scope of the Deprotonative Functionalization Reaction of Pyridine Derivatives ${ }^{a, b}$

a) Reactions were conducted on a $0.2 \mathrm{mmol}$ scale. ${ }^{b)}$ Isolated yields. ${ }^{c)}$ Reactions were conducted using CsF (20 mol \%) and N(TMS) 3 (2.0 equiv). 


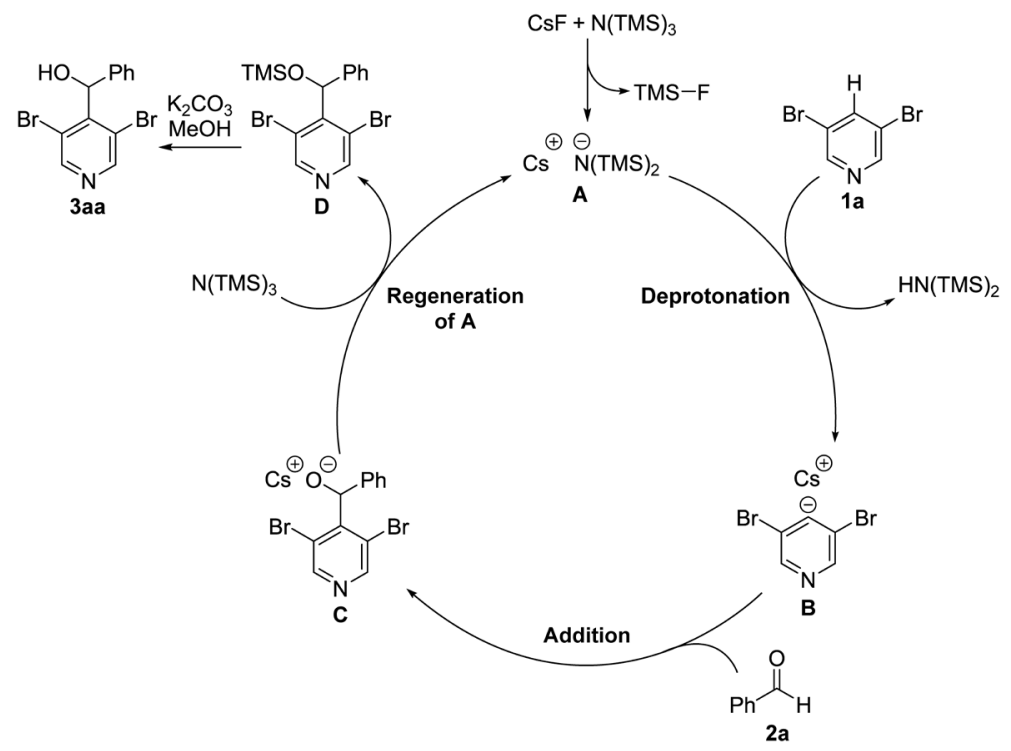

Fig. 3. Proposed Mechanism for the Deprotonative Functionalization of Pyridine Derivatives

yield. 2-Naphthaldehyde (2j) furnished product 3aj in $92 \%$ yield. Reaction of 2,6-dimethylbenzaldehyde (2k) also took place in $78 \%$ yield. The use of heteroarylaldehydes, 2-formylbenzothiophene (2l) and 3-formylpyridine (2m), led to the formations of 3al and 3am in $47 \%$ and $69 \%$ yields, respectively. Enolizable cyclohexanecarboxaldehyde (2n) was also used in the reaction and resulted in the formation of product $3 \mathbf{a n}$ in $73 \%$ yield. $^{36)}$

The proposed mechanism for the deprotonative functionalization reaction is shown in Fig. 3. Initially, amide-base $\mathbf{A}$ is generated in situ from $\mathrm{CsF}$ and $\mathrm{N}(\mathrm{TMS})_{3}$, ${ }^{31)}$ which performs the deprotonation of $\mathbf{1 a}$ to give pyridyl anion species B. Subsequently, B couples with $\mathbf{2 a}$ to form alkoxide $\mathbf{C}$. Then, the reaction of $\mathbf{C}$ and $\mathrm{N}(\mathrm{TMS})_{3}$ occurs to provide silyl ether $\mathbf{D}$ and regenerate $\mathbf{A}$ to complete the catalytic cycle. ${ }^{37)}$

In summary, a catalytic system consisting of an amide-base generated in situ allows the coupling of a range of pyridine derivatives to be performed under ambient conditions. 3,5-Dihalopyridines and 3-chloro-5-(trifluoromethyl)pyridine react efficiently under these reaction conditions. In addition, a diverse range of aldehydes, which include arylaldehydes bearing a variety of substituents (i.e., methyl, methoxy, dimethylamino, chloro, bromo, and ester moieties) and heteroarylaldehydes as well as pivalaldehyde and cyclohexanecarboxaldehyde, were used in the reaction.

Acknowledgments This work was financially supported by JSPS KAKENHI Grant Number 19H03346 (YK), JSPS KAKENHI Grant Number 17K15419 (MS), JSPS KAKENHI Grant Number 19K06967 (MS), Grand for Basic Science Research Projects from The Sumitomo Foundation (MS), Yamaguchi Educational and Scholarship Foundation (MS), NIPPON SHOKUBAI Award in Synthetic Organic Chemistry, Japan (MS), and also the Platform Project for Supporting Drug Discovery and Life Science Research funded by Japan Agency for Medical Research and Development (AMED) (MS, KNK, and YK).

Conflict of Interest The authors declare no conflict of interest.

Supplementary Materials The online version of this article contains supplementary materials.

\section{References and Notes}

1) Gros P. C., Fort Y., Eur. J. Org. Chem., 2009, 4199-4209 (2009). 2) Gros P. C., Fort Y., Eur. J. Org. Chem., 2002, 3375-3383 (2002). 3) Mongin F., Quéguiner G., Tetrahedron, 57, 4059-4090 (2001). 4) El-Hiti G. A., Smith K., Hegazy A. S., Heterocycles, 91, 479-504 (2015).

5) Schlosser M., Mongin F., Chem. Soc. Rev., 36, 1161-1172 (2007).

6) Murakami K., Yamada S., Kaneda T., Itami K., Chem. Rev., 117, 9302-9332 (2017).

7) Taag B., Mosrin M., Ila H., Malakhov V., Knochel P., Angew. Chem. Int. Ed., 50, 9794-9824 (2011).

8) Transition-metal catalysis has also been studied for the functionalization of pyridines: Nakao Y., Synthesis, 3209-3219 (2011). Also see the refs. 6,9 , and 10 .

9) Stephens D. E., Larionov O. V., Tetrahedron, 71, 8683-8716 (2015).

10) Das R., Kapur M. Asian, J. Org. Chem., 7, 1217-1235 (2018).

11) Kondo Y., Shilai M., Uchiyama M., Sakamoto T., J. Am. Chem. Soc., 121, 3539-3540 (1999).

12) Krasovskiy A., Krasovskaya V., Knochel P., Angew. Chem. Int. Ed., 45, 2958-2961 (2006).

13) Mosrin M., Knochel P., Org. Lett., 11, 1837-1840 (2009).

14) Wunderlich S. H., Knochel P., Angew. Chem. Int. Ed., 46, 76857688 (2007).

15) Awad H., Mongin F., Trécourt F., Quéguiner G., Marsais F., Tetrahedron Lett., 45, 7873-7877 (2004).

16) Imahori T., Uchiyama M., Sakamoto T., Kondo Y., Chem. Commun., 2450-2451 (2001)

17) Clososki G. C., Rohbogner C. J., Knochel P., Angew. Chem. Int. Ed., 46, 7681-7684 (2007).

18) Rohbogner C. J., Wunderlich S. H., Clososki G. C., Knochel P., Eur. J. Org. Chem., 2009, 1781-1795 (2009).

19) Harford P. J., Peel A. J., Chevallier F., Takita R., Mongin F., Uchiyama M., Wheatley A. E. H., Dalton Trans., 43, 14181-14203 (2014).

20) Nagaradja E., Chevallier F., Roisnel T., Jouikov V., Mongin F., Tetrahedron, 68, 3063-3073 (2012).

21) Haas D., Hammann J. M., Moyeux A., Cahiez G., Knochel P., Syn- 
lett, 26, 1515-1519 (2015).

22) Wunderlich S. H., Bresser T., Dunst C., Monzon G., Knochel P., Synthesis, 2670-2678 (2010).

23) We have also reported the deprotonative functionalization of 3-bromopyridine using phosphazene base $t$-Bu-P4 with $\mathrm{ZnI} 2$. See: Imahori T., Kondo Y., J. Am. Chem. Soc., 125, 8082-8083 (2003).

24) Inamoto K., Okawa H., Taneda H., Sato M., Hirono Y., Yonemoto M., Kikkawa S., Kondo Y., Chem. Commun., 48, 9771-9773 (2012).

25) Inamoto K., Okawa H., Kikkawa S., Kondo Y., Tetrahedron, 70, 7917-7922 (2014).

26) Taneda H., Inamoto K., Kondo Y., Chem. Commun., 50, 6523-6525 (2014).

27) Shigeno M., Fujii Y., Kajima A., Nozawa-Kumada K., Kondo Y., Org. Process Res. Dev., 23, 443-451 (2019).

28) Shigeno M., Nakaji K., Nozawa-Kumada K., Kondo Y., Org. Lett., 21, 2588-2592 (2019).

29) Shigeno M., Okawa T., Imamatsu M., Nozawa-Kumada K., Kondo Y., Chem. Eur. J., 25, 10294-10297 (2019).

30) Shigeno M., Kai Y., Yamada T., Hayashi K., Nozawa-Kumada K., Denneval C., Kondo Y., Asian J. Org. Chem., 7, 2082-2086 (2018).

31) Large S., Roques N., Langlois B. R., J. Org. Chem., 65, 8848-8856
(2000).

32) Hu M., Gao B., Ni C., Zhang L., Hu J., J. Fluor. Chem., 155, 52-58 (2013).

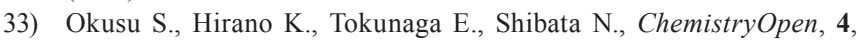
581-585 (2015).

34) Gao B., Zhao Y., Hu M., Ni C., Hu J., Chem. Eur. J., 20, 7803-7810 (2014).

35) $\overline{\mathrm{Gu}}$ and Bayburt have studied the deprotonative functionalization of 1a at the 4-position using LDA as a base under cryogenic conditions, see: Gu Y. G., Bayburt E. K., Tetrahedron Lett., 37, 2565-2568 (1996). Knochel and colleagues reported that the deprotonation of $1 \mathrm{a}$ occurs at the 2-position using $\mathrm{TMPMgCl} \cdot \mathrm{LiCl}$, see ref. 12).

36) Methyl iodide, benzophenone, and methyl benzoate were also employed as electrophiles in the reaction with $\mathbf{1 a}$, however, which did not give the coupling products (results not shown).

37) When the reaction of $\mathbf{1 a}$ and $\mathbf{2} \mathbf{a}$ was carried out in the presence of a radical scavenger of 2,2,6,6-tetramethylpiperidine-1-oxyl (TEMPO), 3aa was obtained in $86 \%$ yield (Chart S1). The result suggests that a radical mechanism is not involved in the reaction. 